\title{
Obesity-related loci in TMEM18, CDKAL1 and FAIM2 are associated with obesity and type 2 diabetes in Chinese Han patients
}

\author{
Jing Kang ${ }^{1}$, Ren-Chu Guan², Ying Zhao ${ }^{1}$ and Yan Chen ${ }^{1 *}$
}

\begin{abstract}
Background: Several obesity susceptibility loci in genes, including GNPDA2, SH2B1, TMEM18, MTCH2, CDKAL1, FAIM2, and MC4R, have been identified by genome-wide association studies. The purpose of this study was to investigate whether these loci are associated with the concurrence of obesity and type 2 diabetes in Chinese Han patients.

Methods: Using the SNaPshot technique, we genotyped seven single nucleotide polymorphisms (SNPs) in 439 Chinese patients living in Northeast China who presented at The Second Hospital of Jilin University. We analyzed the associations between these seven alleles and clinical characteristics.

Results: Risk alleles near TMEM18 (rs6548238) were associated with increased waist circumference, waist/hip ratio, body mass index (BMI), fasting plasma glucose, hemoglobin A1c, diastolic blood pressure, triglycerides, total cholesterol, and low-density lipoprotein-cholesterol; risk alleles of CDKAL1 (rs7754840) were associated with increased waist circumference and waist/hip ratio; and FAIM2 (rs7138803) risk alleles were linked to increased BMl, diastolic blood pressure, and triglycerides (all $P<0.05$ ). After adjusting for sex and age, loci near TMEM18 (rs6548238) and FAIM2 (rs7138803), but not SH2B1 (rs7498665), near GNPDA2 (rs10938397), MTCH2 (rs10838738) and near MC4R (rs12970134), were associated with increased risk for type 2 diabetes in obese individuals.

Conclusion: We found that loci near TMEM18 (rs6548238), CDKAL1 (rs7754840), and FAIM2 (rs7138803) may be associated with obesity-related indicators, and loci near TMEM18 (rs6548238) and FAIM2 (rs7138803) may increase susceptibility of concurrent type 2 diabetes associated with obesity.
\end{abstract}

Keywords: SNP, Genetic variants, Obesity, Type 2 diabetes

\section{Background}

Type 2 diabetes, a common metabolic disease, is a global pandemic and has spread from developed countries to emerging economies, especially China [1]. Diabetes has become a challenging public health problem in China, affecting 98.4 million adults [2]. A combined effect of genetic and environmental risk factors contributes to the development of type 2 diabetes [3]. Like type 1 diabetes, type 2 diabetes is at least

\footnotetext{
* Correspondence: cheny99@jlu.edu.cn

'Department of Endocrinology, The Second Hospital of Jilin University, No. 218 Ziqiang Street, Changchun 130000, China

Full list of author information is available at the end of the article
}

partially hereditary. Type 2 diabetes is considered a multigenic disorder, and therefore it is challenging to find diabetes susceptibility genes. Rapid advances in sequencing technology during the last 10 years have facilitated the discovery of genetic factors for type 2 diabetes. Single nucleotide polymorphisms (SNPs), common genetic variations, are associated with an increased risk of developing type 2 diabetes. So far, many type 2 diabetes susceptibility loci have been identified using genome-wide association (GWA) studies. Many of those genetic susceptibility loci are associated with beta-cell function and/or insulin sensitivity [4]. Type 2 diabetes has been recognized as a heterogeneous disorder, including

C C The Author(s). 2020 Open Access This article is licensed under a Creative Commons Attribution 4.0 International License, which permits use, sharing, adaptation, distribution and reproduction in any medium or format, as long as you give appropriate credit to the original author(s) and the source, provide a link to the Creative Commons licence, and indicate if changes were made. The images or other third party material in this article are included in the article's Creative Commons licence, unless indicated otherwise in a credit line to the material. If material is not included in the article's Creative Commons licence and your intended use is not permitted by statutory regulation or exceeds the permitted use, you will need to obtain permission directly from the copyright holder. To view a copy of this licence, visit http://creativecommons.org/licenses/by/4.0/ The Creative Commons Public Domain Dedication waiver (http://creativecommons.org/publicdomain/zero/1.0/) applies to the data made available in this article, unless otherwise stated in a credit line to the data. 
obese and non-obese types. Therefore, obese and non-obese type 2 diabetic patients may have distinct genetic susceptibility loci.

Beyond genetic susceptibility, type 2 diabetes is closely related to lifestyle factors, such as obesity. Obesity results from excess body fat accumulation and is a major risk factor for type 2 diabetes. Obesity is partially due to environmental factors and lifestyle choices, but is also attributed to genetic susceptibility. To date, GWA analyses have identified more than thirty susceptibility loci robustly associated with obesity measured by body mass index (BMI). Those loci are in or near genes, including GNPDA2, SH2B1, TMEM18, MTCH2, CDKAL1, FAIM2, and $M C 4 R$ [5-8]. It has been reported that the genotype-phenotype association varies in diverse groups of patients, and results need to be verified in a specific population [9]. Most of these obesity risk loci are associated with pattern and content of food intake. For example, obesity risk alleles in $M C 4 R$ were shown to be associated with an increased caloric intake and a higher percentage of calories from fat [10]; $S H 2 B 1$ obesity risk alleles were linked to increased fat intake [11]. However, it is unknown whether these obesity susceptibility loci are associated with the development of type 2 diabetes in obese patients.

This study aimed to investigate the association of these seven obesity susceptibility loci with being overweight and obesity in the Chinese Han population living in Northeast China and whether these risk loci are associated with the concurrence of obesity and type 2 diabetes.

\section{Methods}

\section{Study population}

A total of 249 patients, who had been diagnosed with T2DM in the Department of Endocrinology at the Second Hospital of Jilin University during the period from October 2015 to October 2017, were enrolled in the study. Inclusion criteria included: (1) age 18-65 years; (2) compliance with standard treatment guidelines for T2DM, issued by the WHO diagnostic criteria in 1999 [12]. (3) $B M I \geq 24 \mathrm{~kg} / \mathrm{m}^{2}$. Patients with ketosis during the last 6 months or impaired hepatic and renal function were excluded. Patients with type 1 diabetes, gestational diabetes, and other secondary diabetes were also excluded. According to the 2017 edition of the Chinese guidelines [13] for the prevention and treatment of type 2 diabetes, overweight and obesity were defined as $24 \leq$ $\mathrm{BMI}<28 \mathrm{~kg} / \mathrm{m}^{2}$ and $\mathrm{BMI} \geq 28 \mathrm{~kg} / \mathrm{m}^{2}$, respectively. Using these criteria, the study included 126 patients with type 2 diabetes who were overweight (male: 72; age: $50.38 \pm$ 14.47), 123 patients with type 2 diabetes and obesity (male: 93; age: $47.71 \pm 16.28$ ). And 190 healthy participants (male: 115 ; age: $44.24 \pm 16.84$ ) who had undergone physical examination during the same period. All subjects were genetically unrelated Han Chinese individuals living in Northeast China. The study protocol was approved by the Institutional Review Board of The Second Hospital of Jilin University. Written informed consent was obtained from every participant.

\section{Anthropometric and laboratory measurements}

Anthropometric parameters, including height, body weight, waist circumference, hip circumference, and systolic and diastolic blood pressure, were measured according to the standard protocol, and BMI was calculated using the formula: weight / squared height $\left(\mathrm{kg} / \mathrm{m}^{2}\right)$. Peripheral venous blood samples were drawn from the subjects after 8 to $12 \mathrm{~h}$ fasting. Plasma glucose, insulin, hemoglobin A1c (HbA1c), triglycerides (TG), total cholesterol (TC), low-density lipoprotein cholesterol (LDL-C), and high-density lipoprotein cholesterol (HDL-C) were measured using an automated biochemical analyzer. Insulin resistance index (HOMA-IR) was calculated using the formula: fasting glucose $(\mathrm{mmol} / \mathrm{L})$ $\mathrm{x}$ fasting insulin $(\mu \mathrm{U} / \mathrm{L}) / 22.5$; insulin sensitivity index (HOMA-IS) was calculated using the formula: 22.5 / fasting glucose $(\mathrm{mmol} / \mathrm{L}) \mathrm{x}$ fasting insulin $(\mu \mathrm{U} / \mathrm{L})$.

\section{SNPs selection and genotyping}

Seven SNPs, including rs10938397 (Near GNPDA2), rs7498665 (SH2B1), rs6548238 (Near TMEM18), rs10838738 (MTCH2), rs7754840 (CDKAL1), rs7138803 (FAIM2), and rs12970134 (Near MC4R) reported to be associated with obesity in GWA studies were selected for genotyping [5-8].

Genomic DNA was extracted from the leukocyte pellets of the subjects' peripheral blood samples using the Blood Genomic DNA mini kit (CWBIO, Beijing, China) according to the manufacturer's protocol. Genotyping was performed using the $\mathrm{SNaPshot}$ technology from the Beijing Genomics Institute (BGI, Beijing, China). Primer and probe sequences for each SNP are listed in Tables 1 and 2 .

\section{Statistical analysis}

Continuous variables are expressed as mean \pm standard error (SE). Student's t-test and Wilcoxon signed-rank test were used for comparison between two groups in variables which were normally and not normally distributed, respectively. Categorical variables are expressed as frequencies (percentages), and comparisons were assessed using Chi-square test or Fisher's exact test. The associations between the candidate SNPs and type 2 diabetes were analyzed using univariant logistic regressions. Multivariant logistic regressions were used to analyze the associations between the significant candidate SNPs and type 2 diabetes after adjusting for age and sex. All tests were twotailed. A $P$ value $<0.05$ was considered statistically 
Table 1 PCR primers

\begin{tabular}{ll}
\hline Primers & Sequences \\
\hline rs10938397-F & AGCCGGGCATGTAAACTG \\
rs10938397-R & TTGCCAAAGGACATAGCT \\
rs6548238-F & ATTTAGGTGCCTTGATTG \\
rs6548238-R & GAGCCAGTTGTAGGGATG \\
rs7498665-F & ACAGGGTAGACTGCTGGTGA \\
rs7498665-R & TACCTGTGGCTGTTTCCG \\
rs10838738-F & AAGTAGACGGCGAGACAG \\
rs10838738-R & TCAGATTTCGGAGGATG \\
rs7754840-F & GGGGAAGAAGTAGTAATG \\
rs7754840-R & AAGCTGCTCTGAACATAC \\
rs7138803-F & GCCCTTGATTCCTTCTC \\
rs7138803-R & CCTCTGCCACCCACTAAC \\
rs12970134-F & AAAGGTGGCTTCTTAGATGA \\
rs12970134-R & AGATAGGCAGTGTGGAGAC \\
\hline
\end{tabular}

significant. All statistical analyses were performed using SPSS18.0 for windows (SPSS, Inc., Chicago, Illinois).

The sample size was calculated as follows: alpha was set as 0.05 , beta was set as 0.20 , OR was set as $2.0, \mathrm{P} 1$ was set as $24 \%$ according to a previous report [14], and P0 was set as $12 \%$ according to a previous report [15]. Then the sample size was calculated using the following formula:

$$
N=\frac{\left[Z_{a} \times \sqrt{2 \bar{P}(1-\bar{P})+Z_{\beta}} \sqrt{P_{1}\left(1-P_{1}\right)+P_{0}\left(I-P_{0}\right)}\right]}{\left(P_{1}-P_{0}\right)^{2}}
$$

It came out that at least 124 participants were needed in healthy control and 247 were needed in T2DM group. Finally, 190 in healthy control and 249 in T2DM group were enrolled.

Table 2 Single base extension primers

\begin{tabular}{ll}
\hline Primers & Sequences \\
\hline rs10938397- & CACACCAAAATGTTITACTTTACTTCTCATGGGA \\
YF2 & \\
rs6548238- & AAGTCCACAGCTGGGAGCACAGGGA \\
YF2 & \\
rs7498665- & CCCCCAGAGTTGCCCCCCGCATCCCCATTGAAGAGGG \\
YF3 & ACCCCCA \\
rs10838738- & TAAAAACTGTTCCATTCCTAGGCAC \\
YF2 & \\
rs12970134- & TATTTCGGTTCTAAGCAACAGATACTGATACTGACTCTTACC \\
YF2 & AAACAAAGCATGA \\
rs7138803- & TATGATTCTATGAAATACTITGCACAGCAGGGTGA \\
YR2 & \\
rs7754840- & AAAATCAACTGCTTGCTGTTGGGGAAGAAGTAGTAATG \\
YF2 & TTGGAAA \\
\hline
\end{tabular}

\section{Results}

\section{Clinical characteristics}

The general clinical characteristics of subjects in the healthy control, type 2 diabetes with overweight, and type 2 diabetes with obesity groups are presented in Table 3. The average age was similar among the three groups. The percentage of males was significantly higher in the obese diabetes group compared to the healthy control and overweight diabetes groups (both $P<0.05$ ). Compared to healthy controls, type 2 diabetic patients with overweight or obesity had significantly increased waist circumference, waist/hip ratio, BMI, fasting plasma glucose, HbA1c, systolic and diastolic blood pressure, TG, TC, LDL-C, fasting plasma insulin, HOMA-IR, and HOMA-IS and decreased HDL-C (all $P<0.05$ ). However, these parameters were not significantly different between overweight and obesity groups.

\section{Genotype distribution}

The genotypes of these seven loci in healthy controls and type 2 diabetic patients with overweight and obesity are shown in Table 4. At the locus near GNPDA2 (rs10938397), the AA genotype was most abundant in patients with overweight and type 2 diabetes (50.0\%), and GG was most abundant in healthy controls (21.1\%). At the SH2B1 (rs7498665) locus, the AA genotype was most abundant in patients with overweight and type 2 diabetes (42.9\%), and GG was most abundant in obese diabetic patients $(24.4 \%)$. At the locus near TMEM18 (rs6548238), the CC genotype was most abundant in patients with overweight and type 2 diabetes (76.2\%), and TT was most abundant in healthy controls (60.5\%). At the MTCH2 (rs10838738) locus, both AA (57.1\%) and GG (19.1\%) genotypes were most abundant in patients with overweight and type 2 diabetes. At the FAIM2 (rs7138803) locus, the AA genotype was most abundant in patients with overweight and type 2 diabetes (14.3\%), and TT was most abundant in healthy controls (76.3\%). At the CDKAL1 (rs7754840) and the near MC4R (rs12970134) loci, the genotype distribution was not significantly different among these three groups.

\section{Association between genotype and clinical characteristics} At the near GNPDA2 (rs10938397), SH2B1 (rs7498665), and $M T C H 2$ (rs10838738) loci, there were no significant differences in clinical characteristics between genotypes $\mathrm{AA}$ and GG + AG. At the locus near MC4R (rs12970134), clinical characteristics were similar between genotypes GG and GG + AG. As shown in Table 5, compared with patients harboring $\mathrm{TT}$ at the locus near TMEM18 (rs6548238), patients with $\mathrm{CC}+\mathrm{CT}$ genotypes had increased waist circumference, waist/hip ratio, BMI, fasting plasma glucose, HbA1c, diastolic blood pressure, TG, TC, and LDL-C, and decreased HOMA-IS and HDL-C (all 
Table 3 Clinical characteristics of healthy controls and type 2 diabetic patients with overweight or obesity

\begin{tabular}{|c|c|c|c|c|c|}
\hline Parameters & Healthy controls $(n=190)$ & Overweight diabetes $(n=126)$ & Obese diabetes $(n=123)$ & $Z / x^{2}$ & $P$ \\
\hline Age & $44.24 \pm 16.84$ & $50.38 \pm 14.47$ & $47.71 \pm 16.28$ & 1.50 & 0.227 \\
\hline Male/Female & $115 / 75$ & $72 / 54$ & $90 / 30^{* \#}$ & 6.68 & 0.036 \\
\hline Waist circumference $(\mathrm{cm})$ & $84.24 \pm 14.71$ & $97.79 \pm 15.90^{*}$ & $100.07 \pm 14.88^{*}$ & 12.41 & $<0.001$ \\
\hline Waist/hip ratio & $0.89 \pm 0.34$ & $1.13 \pm 0.33^{*}$ & $1.18 \pm 0.26^{*}$ & 8.19 & $<0.001$ \\
\hline BMI $\left(\mathrm{kg} / \mathrm{m}^{2}\right)$ & $22.44 \pm 4.50$ & $27.07 \pm 4.23^{*}$ & $28.30 \pm 4.51^{*}$ & 18.64 & $<0.001$ \\
\hline FPG $(\mathrm{mmol} / \mathrm{l})$ & $7.33 \pm 2.67$ & $11.21 \pm 3.69^{*}$ & $11.53 \pm 3.69^{*}$ & 18.42 & $<0.001$ \\
\hline HbA1c (\%) & $7.83 \pm 3.16$ & $11.29 \pm 3.77^{*}$ & $10.18 \pm 3.40^{*}$ & 10.32 & $<0.001$ \\
\hline $\mathrm{SBP}(\mathrm{mmHg})$ & $113.61 \pm 13.65$ & $137.10 \pm 22.73^{*}$ & $137.76 \pm 20.03^{*}$ & 19.78 & $<0.001$ \\
\hline $\mathrm{DBP}(\mathrm{mmHg})$ & $75.94 \pm 9.57$ & $86.64 \pm 10.72^{*}$ & $86.76 \pm 9.00^{*}$ & 15.67 & $<0.001$ \\
\hline $\mathrm{TG}(\mathrm{mmol} / \mathrm{L})$ & $2.70 \pm 1.58$ & $5.48 \pm 4.81^{*}$ & $5.18 \pm 4.52^{*}$ & 5.77 & 0.004 \\
\hline $\mathrm{TC}(\mathrm{mmol} / \mathrm{L})$ & $3.80 \pm 1.75$ & $5.81 \pm 2.38^{*}$ & $6.04 \pm 2.22^{*}$ & 12.88 & $<0.001$ \\
\hline $\mathrm{HDL}-\mathrm{C}(\mathrm{mmol} / \mathrm{L})$ & $1.31 \pm 0.66$ & $0.85 \pm 0.34^{*}$ & $0.93 \pm 0.39^{*}$ & 10.48 & $<0.001$ \\
\hline LDL-C (mmol/L) & $2.36 \pm 0.88$ & $3.08 \pm 0.98^{*}$ & $2.99 \pm 0.90^{*}$ & 6.99 & $<0.001$ \\
\hline FINS $(\mu \mid \mathrm{U} / \mathrm{mL})$ & $12.45 \pm 6.95$ & $24.80 \pm 19.79^{*}$ & $23.89 \pm 12.23^{*}$ & 9.19 & $<0.001$ \\
\hline HOMA-IR & $4.66 \pm 3.67$ & $11.93 \pm 9.45^{*}$ & $11.36 \pm 7.27^{*}$ & 11.85 & $<0.001$ \\
\hline HOMA-IS & $0.01(0.00,0.02)$ & $0.013(0.01,0.02)^{*}$ & $0.012(0.00,0.02)$ & 10.39 & 0.006 \\
\hline
\end{tabular}

FPG fasting plasma glucose, FINS fasting insulin. ${ }^{*} P<0.05$ vs. healthy controls; ${ }^{*} P<0.05$ vs. overweight diabetes

Table 4 Genotypes of seven genetic loci

\begin{tabular}{|c|c|c|c|c|c|c|c|}
\hline$\overline{S N P}$ & Locus & Genotype & Healthy controls n (\%) & Overweight diabetes n (\%) & Obesity diabetes $\mathrm{n}(\%)$ & $x^{2}$ & $P$ \\
\hline \multirow[t]{3}{*}{ rs10938397 } & \multirow[t]{3}{*}{ Near GNPDA2 } & AA & $85(44.7)$ & $63(50.0)$ & $54(43.9)$ & \multirow[t]{3}{*}{4.45} & \multirow[t]{3}{*}{$<0.001$} \\
\hline & & $A G$ & $65(34.2)$ & $45(35.7)$ & $51(41.5)$ & & \\
\hline & & GG & $40(21.1)$ & $18(14.3)$ & $18(14.6)$ & & \\
\hline \multirow[t]{3}{*}{ rs7498665 } & \multirow[t]{3}{*}{$\mathrm{SH} 2 \mathrm{~B} 1$} & AA & $75(39.5)$ & $54(42.9)$ & $30(24.4)$ & \multirow[t]{3}{*}{24.73} & \multirow[t]{3}{*}{$<0.001$} \\
\hline & & $A G$ & $70(36.8)$ & $63(50.0)$ & $63(51.2)$ & & \\
\hline & & GG & $45(23.7)$ & $9(7.1)$ & $30(24.4)$ & & \\
\hline \multirow[t]{3}{*}{ rs6548238 } & \multirow[t]{3}{*}{ Near TMEM18 } & $\pi$ & $115(60.5)$ & $18(14.3)$ & $57(46.3)$ & \multirow[t]{3}{*}{70.53} & \multirow[t]{3}{*}{$<0.001$} \\
\hline & & $\mathrm{CT}$ & $5(2.6)$ & $12(9.5)$ & $12(9.8)$ & & \\
\hline & & $\mathrm{CC}$ & $70(36.8)$ & $96(76.2)$ & $54(43.9)$ & & \\
\hline \multirow[t]{3}{*}{ rs10838738 } & \multirow[t]{3}{*}{$\mathrm{MTCH} 2$} & $\mathrm{AA}$ & $95(50.0)$ & $72(57.1)$ & $48(39.0)$ & \multirow[t]{3}{*}{37.74} & \multirow[t]{3}{*}{$<0.001$} \\
\hline & & $A G$ & $90(47.4)$ & $30(23.8)$ & $57(46.3)$ & & \\
\hline & & GG & $5(2.6)$ & $24(19.1)$ & $18(14.6)$ & & \\
\hline \multirow[t]{3}{*}{ rs7754840 } & \multirow[t]{3}{*}{ CDKAL1 } & $\mathrm{CC}$ & $45(23.7)$ & $27(21.5)$ & $21(17.1)$ & \multirow[t]{3}{*}{6.73} & \multirow[t]{3}{*}{0.15} \\
\hline & & CG & $65(34.2)$ & $57(45.2)$ & $57(46.3)$ & & \\
\hline & & GG & $80(42.1)$ & $42(33.3)$ & 45 (36.6) & & \\
\hline \multirow[t]{3}{*}{ rs7138803 } & \multirow[t]{3}{*}{ FAIM2 } & GG & $145(76.3)$ & $66(52.4)$ & $63(51.2)$ & \multirow[t]{3}{*}{32.16} & \multirow[t]{3}{*}{$<0.001$} \\
\hline & & $A G$ & $40(21.1)$ & $42(33.3)$ & 45 (36.6) & & \\
\hline & & $\mathrm{AA}$ & $5(2.6)$ & $18(14.3)$ & $15(12.2)$ & & \\
\hline \multirow[t]{3}{*}{ rs12970134 } & \multirow[t]{3}{*}{ Near MC4R } & GG & 105 (55.3) & $81(64.3)$ & 75 (61.0) & \multirow[t]{3}{*}{7.58} & \multirow[t]{3}{*}{0.108} \\
\hline & & $A G$ & 60 (31.6) & 39 (31.0) & $39(31.7)$ & & \\
\hline & & $\mathrm{AA}$ & 25 (13.2) & $6(4.8)$ & $9(7.3)$ & & \\
\hline
\end{tabular}


$P<0.05)$. Patients with $\mathrm{CC}+\mathrm{CG}$ at the CDKAL1 (rs7754840) locus had higher waist circumference and waist/hip ratio compared to patients with the GG genotype (both $P<0.05)$. At the FAIM2 (rs7138803) locus, patients with AA + AG genotypes had increased BMI, fasting plasma glucose, diastolic blood pressure, TG, and fasting plasma insulin compared to patients harboring GG (all $P<0.05$ ).

Univariate logistic regression analysis showed that the loci near TMEM18 (rs6548238) and FAIM2 (rs7138803) were associated with type 2 diabetes. At the locus near TMEM18 (rs6548238), subjects with CC + CT genotypes had an increased risk of diabetes compared to the TT genotype (odds ratio $(\mathrm{OR})=2.44,95 \%$ confidence interval (CI): 1.11-5.37 $P=0.026$ ). At the FAIM2 (rs7138803) locus, individuals with AA + AG genotype had a higher diabetes risk compared to those with the GG genotype (OR $=2.72,95 \%$ CI: $1.15-6.45, P=0.023)$. However, the loci near GNPDA2 (rs10938397), SH2B1 (rs7498665), MTCH2 (rs10838738), CDKAL1 (rs7754840), and near $M C 4 R$ (rs12970134) were not significantly associated with the concurrence of type 2 diabetes (all $P>0.05$, Table 6).

The loci that were significantly associated with diabetes risk in univariate logistic analysis were used in a multivariant regression analysis model to further study their association with type 2 diabetes. After adjusting for age and sex, the loci near TMEM18 (rs6548238) and
FAIM2 (rs7138803) were significantly associated with diabetes (Table 7). Compared to the TT genotype, the subjects with CC + CT genotypes of rs6548238 had an increased diabetes risk with an OR of 2.27 (95\% CI: 1.00-5.13, $P=0.05$ ). For the FAIM2 (rs7138803) locus, subjects with AA + AG had an elevated risk for type 2 diabetes compared to the GG genotype (OR $=2.67,95 \%$ CI: $1.09-6.59, P=0.033)$.

\section{Discussion}

Many obesity susceptibility loci identified from largescale GWA studies have been confirmed in specific populations. This study investigated the association of seven common obesity risk loci with overweight/obesity and type 2 diabetes in a Chinese Han population. We found that the loci near TMEM18 (rs6548238) and CDKAL1 (rs7754840) were associated with increased waist circumference and waist/hip ratio, and FAIM2 (rs7138803) was associated with increased BMI, diastolic blood pressure, and TG. After adjusting for age and sex, CT or CC genotypes at the locus near TMEM18 (rs6548238) and AA or AG genotypes of the FAIM2 (rs7138803) locus were associated with type 2 diabetes. In addition, these association relationships were dependent on BMI.

In this study, we found that $\mathrm{CC}$ or $\mathrm{CT}$ genotypes at the locus near TMEM18 (rs6548238) were most frequent in overweight/obese patients with type 2 diabetes. Allele

Table 5 Comparisons of clinical characteristics among genotypes rs7754840, rs7138803, and rs6548238

\begin{tabular}{|c|c|c|c|c|c|c|c|c|c|}
\hline & \multicolumn{2}{|l|}{ rs7754840 } & \multirow[t]{2}{*}{$P$} & \multicolumn{2}{|l|}{ rs7138803 } & \multirow[t]{2}{*}{ P } & \multicolumn{3}{|l|}{ rs6548238 } \\
\hline & $\overline{C C+C G}$ & GG & & $\overline{A A+A G}$ & GG & & $\overline{C C}+C T$ & $\pi$ & $P$ \\
\hline $\begin{array}{l}\text { Waistcircumference } \\
(\mathrm{cm})\end{array}$ & $96.68 \pm 17.31$ & $90.29 \pm 14.56$ & 0.040 & $97.11 \pm 16.42$ & $92.53 \pm 16.53$ & 0.139 & $97.27 \pm 16.84$ & $90.75 \pm 15.66$ & 0.030 \\
\hline Waist/hip ratio & $1.11 \pm 0.36$ & $0.97 \pm 0.25$ & 0.027 & $1.09 \pm 0.30$ & $1.04 \pm 0.35$ & 0.345 & $1.15 \pm 0.33$ & $0.95 \pm 0.29$ & 0.001 \\
\hline $\mathrm{BMI}\left(\mathrm{kg} / \mathrm{m}^{2}\right)$ & $26.48 \pm 4.98$ & $25.98 \pm 5.80$ & 0.612 & $27.94 \pm 4.94$ & $25.25 \pm 5.25$ & 0.006 & $26.94 \pm 4.57$ & $22.52 \pm 5.98$ & 0.023 \\
\hline $\mathrm{FPG}(\mathrm{mmol} / \mathrm{L})$ & $10.07 \pm 4.00$ & $10.14 \pm 3.67$ & 0.925 & $10.97 \pm 3.77$ & $9.54 \pm 3.85$ & 0.046 & $11.01 \pm 3.80$ & $9.01 \pm 3.69$ & 0.004 \\
\hline $\mathrm{HbA} 1 \mathrm{c}, \%$ & $9.90 \pm 3.94$ & $9.72 \pm 3.36$ & 0.799 & $10.30 \pm 3.74$ & $9.53 \pm 3.70$ & 0.268 & $10.70 \pm 4.02$ & $8.78 \pm 3.05$ & 0.004 \\
\hline $\mathrm{SBP}(\mathrm{mm} \mathrm{Hg})$ & $132.91 \pm 23.98$ & $124.93 \pm 17.85$ & 0.039 & $\begin{array}{l}130.00 \\
(112.00,115.00)\end{array}$ & $\begin{array}{l}122.00 \\
(110.00,150.00)\end{array}$ & 0.413 & $\begin{array}{l}131.39 \pm \\
22.03\end{array}$ & $128.20 \pm 22.39$ & 0.432 \\
\hline $\mathrm{DBP}(\mathrm{mm} \mathrm{Hg})$ & $84.03 \pm 11.14$ & $82.13 \pm 10.60$ & 0.360 & $86.45 \pm 9.91$ & $81.34 \pm 11.16$ & 0.012 & $85.91 \pm 9.91$ & $80.22 \pm 11.39$ & 0.004 \\
\hline TG (mmol/L) & $4.61 \pm 4.38$ & $4.32 \pm 3.69$ & 0.705 & $\begin{array}{l}3.66 \\
(1.98,7.13)\end{array}$ & $2.62(1.42,4.84)$ & 0.041 & $5.46 \pm 4.80$ & $3.36 \pm 2.76$ & 0.005 \\
\hline $\mathrm{TC}(\mathrm{mmol} / \mathrm{L})$ & $5.39 \pm 2.60$ & $5.38 \pm 2.60$ & 0.44 & $5.38 \pm 2.60$ & $4.93 \pm 2.38$ & 0.324 & $5.88 \pm 2.45$ & $4.51 \pm 1.99$ & 0.001 \\
\hline $\mathrm{HDL}-\mathrm{C}(\mathrm{mmol} / \mathrm{L})$ & $1.05 \pm 0.54$ & $0.98 \pm 0.47$ & 0.455 & $\begin{array}{l}0.92 \\
(0.58,1.06)\end{array}$ & $0.97(0.70,1.22)$ & 0.066 & $0.85 \pm 0.36$ & $1.23 \pm 0.59$ & 0.001 \\
\hline LDL-C (mmol/L) & $2.92 \pm 1.01$ & $2.37 \pm 0.87$ & 0.176 & $2.99 \pm 0.93$ & $2.72 \pm 0.98$ & 0.133 & $2.98 \pm 1.04$ & $2.63 \pm 0.85$ & 0.050 \\
\hline FINS $(\mu \mid \mathrm{U} / \mathrm{mL})$ & $22.27 \pm 17.33$ & $17.82 \pm 10.06$ & 0.076 & $\begin{array}{l}19.60 \\
(16.56,26.72)\end{array}$ & $\begin{array}{l}13.18 \\
(8.72,26.10)\end{array}$ & 0.007 & $21.50 \pm 12.51$ & $19.55 \pm 17.88$ & 0.484 \\
\hline HOMA-IR & $6.81(2.98,14.05)$ & $5.60(3.59,13.86)$ & 0.677 & $\begin{array}{l}10.46 \\
(3.72,15.07)\end{array}$ & $\begin{array}{l}5.35 \\
(2.90,12.68)\end{array}$ & 0.083 & $10.01 \pm 8.52$ & $8.79 \pm 7.31$ & 0.399 \\
\hline HOMA-IS & $0.010(0.000,0.020)$ & $0.010(0.005,0.017)$ & 0.184 & $\begin{array}{l}0.012 \\
(0.010,0.020)\end{array}$ & $\begin{array}{l}0.010 \\
(0.000,0.020)\end{array}$ & 0.662 & $\begin{array}{l}0.010(0.000 \\
0.010)\end{array}$ & $\begin{array}{l}0.016(0.010 \\
0.020)\end{array}$ & 0.001 \\
\hline
\end{tabular}


Table 6 Univariant logistic analysis of the association of seven loci with type 2 diabetes

\begin{tabular}{lllllll}
\hline Loci & $b$ & SE & $P$ & OR & \multicolumn{2}{c}{$95 \% \mathrm{Cl}$} \\
\cline { 6 - 7 } & & & & & Lower & Upper \\
\hline rs10938397 & -0.09 & 0.39 & 0.818 & 0.91 & 0.42 & 1.97 \\
rs7498665 & 0.25 & 0.41 & 0.54 & 1.28 & 0.58 & 2.83 \\
rs6548238 & 0.89 & 0.40 & 0.026 & 2.44 & 1.11 & 5.37 \\
rs10838738 & 0.07 & 0.39 & 0.854 & 1.08 & 0.499 & 2.32 \\
rs7754840 & 0.30 & 0.40 & 0.45 & 1.35 & 0.62 & 2.97 \\
rs7138803 & 1.00 & 0.44 & 0.023 & 2.72 & 1.15 & 6.45 \\
rs12970134 & 0.31 & 0.40 & 0.441 & 1.36 & 0.62 & 2.96 \\
\hline
\end{tabular}

$\mathrm{C}$ was most common in overweight/obese diabetic patients, and CC or CT genotypes were associated with an increased diabetes risk, indicating that allele $\mathrm{C}$ may be a risk factor for concurrent obesity and diabetes. In addition, subjects with $\mathrm{CC}$ or CT genotypes of rs6548238 had elevated waist circumference, waist/hip ratio, BMI, fasting plasma glucose, HbA1c, TG, and TC, but declined HDL-C, suggesting that the locus near TMEM18 (rs6548238) may increase obesity/diabetes risk through inducing metabolic disorders. In 2009, the Genetic Investigation of Anthropometric Traits Consortium conducted a large-scale meta-analysis involving more than 32,000 European subjects and found that the locus near TMEM18 (rs6548238) was associated with obesity, with allele $\mathrm{C}$ being more important than allele $\mathrm{T}$ [16]. This result is consistent with the finding in our population. TMEM18 is widely expressed in several regions of the brain and is particularly abundant in the hypothalamus [17]. It was reported that TMEM18 increases mouse body weight and white/brown fat mass through increasing high-fat food intake [18]. In 2009, Willer et al. first reported that SNPs near TMEM18 were linked to obesity in humans and that the locus near TMEM18 (rs6548238) was associated with increased BMI [16]. This finding was then confirmed in obese adults and children [19-23]. The CT or CC genotypes in the locus near TMEM18 (rs6548238) were not associated with plasma insulin levels. Therefore, we speculated that the

Table 7 Multivariant logistic analysis of the association between genetic loci with diabetes risk

\begin{tabular}{lllllll}
\hline & $b$ & SE & $P$ & OR & \multicolumn{2}{c}{$95 \% \mathrm{Cl}$} \\
\cline { 6 - 7 } & & & & & Lower & Upper \\
\hline Sex & -0.309 & 0.44 & 0.487 & 0.74 & 0.31 & 1.75 \\
Age & -0.43 & 0.43 & 0.314 & 0.647 & 0.28 & 1.51 \\
rs7138803 & 0.98 & 0.46 & 0.033 & 2.67 & 1.09 & 6.59 \\
rs6548238 & 0.82 & 0.42 & 0.05 & 2.27 & 1.00 & 5.13 \\
Constant & 0.68 & 0.64 & 0.29 & 1.97 & & \\
\hline
\end{tabular}

locus near TMEM18 (rs6548238) may increase diabetes risk via inducing obesity and insulin resistance. An experimental study in Drosophila found that TMEM18 affected substrate levels via insulin and glucagon signaling [24]. Further functional studies are needed to understand the mechanisms by which the locus near TMEM18 (rs6548238) regulates the development of obesity and type 2 diabetes.

Our study found that AA or AG genotypes of FAIM2 (rs7138803) were most frequent in overweight/obese patients with type 2 diabetes in a Chinese Han population. Allele A was most common in overweight/obese diabetic patients, and AA or AG genotypes were associated with an increased risk for type 2 diabetes, indicating that allele $\mathrm{A}$ at this locus may be a risk factor for obesity and diabetes. Moreover, the subjects with AA or AG genotypes had increased BMI, fasting plasma glucose, diastolic blood pressure, TG, and fasting plasma insulin compared to those with the AA genotype. A previous large-scale GWA study identified FAIM2 (rs7138803) as being associated with obesity in Caucasian adults [18]. This result was then confirmed in an Asian population [25], where this association was absent in two Chinese populations from Sichuan and Beijing $[26,27]$. These inconsistent findings might be due to differences in ethnicity and sample size. It was reported that FAIM2 is highly expressed in the hippocampus and may be involved in the development of appetite controlling nerves and apoptosis of adipocytes [28]. Therefore, polymorphisms in FAIM2 (rs7138803) are speculated to induce obesity by enhancing appetite and suppressing adipocyte apoptosis, which are consistent with the current study showing an association of risk allele and increased BMI. In this case, the increased risk for diabetes is likely due to obesity. The risk allele of FAIM2 (rs7138803) was associated with increased diastolic blood pressure, which might be secondary to obesity.

Previous studies in European and Asian populations found that CDKAL1 is associated with type 2 diabetes [29-31], and the C allele of rs7754840 was associated with the highest risk for diabetes [25]. Although the function of CDKAL1 is not fully understood, the CDKAL1 protein likely functions similarly to cyclin dependent kinase 5 (CDK5). A recent in vitro study demonstrated that CDK5 caused functional impairment of islet beta cells [32]. In addition, knockout of Cdkal1 in mice impaired first-phase insulin exocytosis in beta cells, likely through regulating $\mathrm{K}_{\mathrm{ATP}}$ channel responsiveness [33]. A study including Finnish men demonstrated that CDKAL1 (rs7754840) was associated with increased risk for type 2 diabetes, likely via impairing insulin secretion [34]. The current study did not show an association between CDKAL1 (rs7754840) and diabetes, which may be due a to relatively small sample size. We found that 
subjects with CC or CG genotypes at the CDKAL1 (rs7754840) locus had increased waist circumstance and waist/hip ratio, indicating that rs7754840 may increase diabetes risk as well as abdominal obesity. This association needs to be further investigated in larger samplesized studies.

Associations of the loci SH2B1 (rs7498665), near GNPDA2 (rs10938397), MTCH2 (rs10838738), and near MC4R (rs12970134) with obesity have been shown in many studies $[25,35,36]$. Morris et al. found that $S H 2 B 1$ is involved in regulating diabetes risk by affecting insulin sensitivity [37]. The locus near GNPDA2 (rs10938397) was associated with increased risk for obesity, which was independent of BMI [38]. A Chinese population study revealed that MC4R (rs12970134) was associated with type 2 diabetes after adjusting for BMI [39]. However, our study did not show that these four loci were associated with obesity and diabetes, which may be due to different ethnic populations. This study included Chinese Han population in Northeast China. In the follow-up work, we will conduct a larger sample size test for financing studies.

\section{Conclusions}

Taken together, among seven common obesity risk loci, the loci near TMEM18 (rs6548238), CDKAL1 (rs7754840), and FAIM2 (rs7138803) are associated with obesity, and loci near TMEM18 (rs6548238) and FAIM2 (rs7138803) are susceptibility loci for obese type 2 diabetes.

\section{Abbreviations}

SNPS: Single nucleotide polymorphisms; GWA: Genome-wide association; HbA1c: Hemoglobin A1c; TG: Triglycerides; TC: Total cholesterol; LDL-C: Lowdensity lipoprotein cholesterol; HDL-C: High-density lipoprotein cholesterol

\section{Acknowledgments}

None.

\section{Authors' contributions}

JK and YC designed the study. JK, RCG, YZ, and YC collected and analyzed the data. JK and RCG drafted and wrote the manuscript. JK and $Y C$ revised the manuscript critically for intellectual content. All authors gave intellectua input to the study and approved the final version of the manuscript.

\section{Funding}

This work was supported by Provincial Department of Education "13th Five Science and Technology Research Projects (JJKH20190193KJ). The authors declare that the funding body was not involved in study design, data collection, analysis, interpretation and writing of the study.

\section{Availability of data and materials}

The datasets generated and/or analysed during the current study are available in the NCBI ClinVar repository, ClinVar accession number: SCV001134937, SCV001160743, SCV001160724.

\section{Ethics approval and consent to participate}

The study protocol was approved by the Institutional Review Board of The Second Hospital of Jilin University. All procedures performed in studies involving human participants were in accordance with the ethical standards of the institutional and national research committee and with the 1964 Helsinki declaration and its later amendments or comparable ethical standards. Written informed consent was obtained from every participant.
Consent for publication

Not Applicable.

\section{Competing interests}

The authors declare that they have no competing interests.

\section{Author details}

${ }^{1}$ Department of Endocrinology, The Second Hospital of Jilin University, No. 218 Ziqiang Street, Changchun 130000, China. ${ }^{2}$ College of Computer Science and Technology, Jilin University, Changchun 130000, China.

Received: 16 February 2019 Accepted: 16 March 2020

Published online: 30 March 2020

\section{References}

1. Zhang T. The effects of economic development and built environment on diabetes in CHINA. Popul Health Metrics. 2017;15:35.

2. Jia W. Diabetes: a challenge for China in the 21st century. Lancet Diabetes Endocrinol. 2014;2:e6-7.

3. Stumvoll M, Goldstein BJ, van Haeften TW. Type 2 diabetes: principles of pathogenesis and therapy. Lancet. 2005;365:1333-46.

4. Voight BF, Scott LJ, Steinthorsdottir V, Morris AP, Dina C, Welch RP, et al. Twelve type 2 diabetes susceptibility loci identified through large-scale association analysis. Nat Genet. 2010;42:579-89.

5. Cuypers KF, Loos RJ, Kvaloy K, Kulle B, Romundstad P, Holmen TL. Obesitysusceptibility loci and their influence on adiposity-related traits in transition from adolescence to adulthood--the HUNT study. PLoS One. 2012;7:e46912.

6. McCaffery JM, Papandonatos GD, Peter I, Huggins GS, Raynor HA, Delahanty $L M$, et al. Obesity susceptibility loci and dietary intake in the look AHEAD trial. Am J Clin Nutr. 2012;95:1477-86.

7. Abadi A, Alyass A. Robiou du Pont S, Bolker B, Singh P, Mohan V, et al. penetrance of polygenic obesity susceptibility loci across the body mass index distribution. Am J Hum Genet. 2017;101:925-38.

8. Zandona MR, Sangalli CN, Campagnolo PD, Vitolo MR, Almeida S, Mattevi VS. Validation of obesity susceptibility loci identified by genome-wide association studies in early childhood in south Brazilian children. Pediatr Obes. 2017;12:85-92.

9. Rosenberg NA, Huang L, Jewett EM, Szpiech ZA, Jankovic I, Boehnke M. Genome-wide association studies in diverse populations. Nat Rev Genet. 2010;11:356-66

10. Qi L, Kraft P, Hunter DJ, Hu FB. The common obesity variant near MC4R gene is associated with higher intakes of total energy and dietary fat, weight change and diabetes risk in women. Hum Mol Genet. 2008;17:3502-8.

11. Bauer F, Elbers CC, Adan RA, Loos RJ, Onland-Moret NC, Grobbee DE, et al. Obesity genes identified in genome-wide association studies are associated with adiposity measures and potentially with nutrient-specific food preference. Am J Clin Nutr. 2009;90:951-9.

12. World Health Orgnization. Definition and diagnosis of diabetes mellitus and intermediate hyperglycemia: report of a WHO/IDF consultation. Geneva: WHO Document Production Services; 2006.

13. Chinese Diabetes Society. Chinese guideline for the prevention and treatment of type 2 diabetes mellitus (2017 edition). Chinese J Diabetes Mellitus. 2018;10:4-51.

14. Wang L, Gao P, Zhang M, Huang Z, Zhang D, Deng Q, et al. Prevalence and ethnic pattern of diabetes and Prediabetes in China in 2013. Jama. 2017; 317:2515-23.

15. Jia W. Obesity in China: its characteristics, diagnostic criteria, and implications. Front Med. 2015;9:129-33.

16. Willer CJ, Speliotes EK, Loos RJ, Li S, Lindgren CM, Heid IM, et al. Six new loci associated with body mass index highlight a neuronal influence on body weight regulation. Nat Genet. 2009;41:25-34.

17. Almen MS, Jacobsson JA, Shaik JH, Olszewski PK, Cedernaes J, Alsio J, et al. The obesity gene, TMEM18, is of ancient origin, found in majority of neuronal cells in all major brain regions and associated with obesity in severely obese children. BMC Med Genet. 2010;11:58

18. Larder R, Sim MFM, Gulati P, Antrobus R, Tung YCL, Rimmington D, et al. Obesity-associated gene TMEM18 has a role in the central control of appetite and body weight regulation. Proc Natl Acad Sci U S A. 2017;114: 9421-6.

19. Thorleifsson G, Walters GB, Gudbjartsson DF, Steinthorsdottir $V$, Sulem $P$ Helgadottir A, et al. Genome-wide association yields new sequence variants 
at seven loci that associate with measures of obesity. Nat Genet. 2009;41: $18-24$.

20. Scherag A, Dina C, Hinney A, Vatin V, Scherag S, Vogel Cl, et al. Two new loci for body-weight regulation identified in a joint analysis of genomewide association studies for early-onset extreme obesity in French and german study groups. PLoS Genet. 2010;6:e1000916.

21. Zhao J, Bradfield JP, Zhang H, Sleiman PM, Kim CE, Glessner JT, et al. Role of BMI-associated loci identified in GWAS meta-analyses in the context of common childhood obesity in European Americans. Obesity (Silver Spring). 2011:19:2436-9.

22. Wang J, Mei H, Chen W, Jiang Y, Sun W, Li F, et al. Study of eight GWASidentified common variants for association with obesity-related indices in Chinese children at puberty. Int J Obes (Lond). 2012;36:542-7.

23. Felix JF, Bradfield JP, Monnereau C, van der Valk RJ, Stergiakouli E, Chesi A, et al. Genome-wide association analysis identifies three new susceptibility loci for childhood body mass index. Hum Mol Genet. 2016;25:389-403.

24. Wiemerslage L, Gohel PA, Maestri G, Hilmarsson TG, Mickael M, Fredriksson $R$, et al. The Drosophila ortholog of TMEM18 regulates insulin and glucagon-like signaling. J Endocrinol. 2016;229:233-43.

25. Hotta K, Nakamura M, Nakamura T, Matsuo T, Nakata Y, Kamohara S, et al. Association between obesity and polymorphisms in SEC16B, TMEM18, GNPDA2, BDNF, FAIM2 and MC4R in a Japanese population. J Hum Genet. 2009:54:727-31.

26. Wu L, Xi B, Zhang M, Shen Y, Zhao X, Cheng H, et al. Associations of six single nucleotide polymorphisms in obesity-related genes with BMI and risk of obesity in Chinese children. Diabetes. 2010;59:3085-9.

27. Huang H, Zeng Z, Zhang L, Liu R, Li X, Qiang O, et al. Implication of genetic variants near TMEM18, BCDIN3D/FAIM2, and MC4R with coronary artery disease and obesity in Chinese: a angiography-based study. Mol Biol Rep. 2012;39:1739-44.

28. Somia NV, Schmitt MJ, Vetter DE, Van Antwerp D, Heinemann SF, Verma IM. LFG: an anti-apoptotic gene that provides protection from Fas-mediated cell death. Proc Natl Acad Sci U S A. 1999;96:12667-72.

29. Steinthorsdottir $V$, Thorleifsson G, Reynisdottir I, Benediktsson R, Jonsdottir T, Walters GB, et al. A variant in CDKAL1 influences insulin response and risk of type 2 diabetes. Nat Genet. 2007:39:770-5.

30. Omori S, Tanaka Y, Takahashi A, Hirose H, Kashiwagi A, Kaku K, et al. Association of CDKAL1, IGF2BP2, CDKN2A/B, HHEX, SLC30A8, and KCNJ11 with susceptibility to type 2 diabetes in a Japanese population. Diabetes. 2008:57:791-5

31. Takeuchi F, Serizawa M, Yamamoto K, Fujisawa T, Nakashima E, Ohnaka K, et al. Confirmation of multiple risk loci and genetic impacts by a genomewide association study of type 2 diabetes in the Japanese population. Diabetes. 2009;58:1690-9.

32. Ubeda M, Rukstalis JM, Habener JF. Inhibition of cyclin-dependent kinase 5 activity protects pancreatic beta cells from glucotoxicity. J Biol Chem. 2006; 281:28858-64

33. Ohara-Imaizumi M, Yoshida M, Aoyagi K, Saito T, Okamura T, Takenaka H, et al. Deletion of CDKAL1 affects mitochondrial ATP generation and firstphase insulin exocytosis. PLoS One. 2010;5:e15553.

34. Stancakova A, Pihlajamaki J, Kuusisto J, Stefan N, Fritsche A, Haring H, et al. Single-nucleotide polymorphism rs 7754840 of CDKAL1 is associated with impaired insulin secretion in nondiabetic offspring of type 2 diabetic subjects and in a large sample of men with normal glucose tolerance. J Clin Endocrinol Metab. 2008:93:1924-30

35. Renstrom F, Payne F, Nordstrom A, Brito EC, Rolandsson O, Hallmans G, et al. Replication and extension of genome-wide association study results for obesity in 4923 adults from northern Sweden. Hum Mol Genet. 2009;18: 1489-96.

36. Ng MC, Tam CH, So WY, Ho JS, Chan AW, Lee HM, et al. Implication of genetic variants near NEGR1, SEC16B, TMEM18, ETV5/DGKG, GNPDA2, LIN7C/BDNF, MTCH2, BCDIN3D/FAIM2, SH2B1, FTO, MC4R, and KCTD15 with obesity and type 2 diabetes in 7705 Chinese. J Clin Endocrinol Metab. 2010; 95:2418-25.

37. Morris DL, Cho KW, Zhou Y, Rui L. SH2B1 enhances insulin sensitivity by both stimulating the insulin receptor and inhibiting tyrosine dephosphorylation of insulin receptor substrate proteins. Diabetes. 2009;58: 2039-47.

38. Xi B, Takeuchi F, Meirhaeghe A, Kato N, Chambers JC, Morris AP, et al. Associations of genetic variants in/near body mass index-associated genes with type 2 diabetes: a systematic meta-analysis. Clin Endocrinol (Oxf). 2014; 81:702-10.

39. Kong X, Zhang X, Zhao Q, He J, Chen L, Zhao Z, et al. Obesity-related genomic loci are associated with type 2 diabetes in a Han Chinese population. PLoS One. 2014;9:e104486.

\section{Publisher's Note}

Springer Nature remains neutral with regard to jurisdictional claims in published maps and institutional affiliations.
Ready to submit your research? Choose BMC and benefit from:

- fast, convenient online submission

- thorough peer review by experienced researchers in your field

- rapid publication on acceptance

- support for research data, including large and complex data types

- gold Open Access which fosters wider collaboration and increased citations

- maximum visibility for your research: over $100 \mathrm{M}$ website views per year

At BMC, research is always in progress.

Learn more biomedcentral.com/submissions 